\title{
Treating people with learning disabilities after physical or sexual abuse
}

\author{
Valerie Sinason
}

It is a sign of the progress we have made in the field of learning disability that it is possible to consider three previously taboo subjects in one paper. Before 1979, there was no published English clinical or theoretical paper which looked at either talking treatments for people with learning disabilities, treatment for those who survived physical and sexual abuse or, specifically, talking treatment for survivors of abuse who also have learning disabilities. Such steps forward bring hope for the future, but also pain concerning the past. How often have emotional and behavioural communications of betrayal and violation been ascribed to 'disability' and not been properly considered because there was no social intellectual context to help us to consider that there might be a reason for them? This also illustrates the need for continuing professional humility and toleration of uncertainty. What painful experiences and communications of our patients are we missing today because of internal and external taboos? How will we feel when we become aware of them in another 10 or 20 years' time?

Taboo subjects that affect us deeply as citizens and professionals often require a paradigm shift to allow emotional and conceptual change. It is therefore useful to examine these taboos more carefully before considering treatment issues. The treatment that we provide is a result of our own contemporary psychological, social and historical experience. Psychoanalysis helps us to understand that the past matters when it is alive in the present. Any patient with a learning disability who disclosed abuse more than 17 years ago was extremely unlikely to receive any treatment. Those who were abused even 10 years ago did not fare much better (Sinason,
1994). This means that large numbers of older adults presenting to our services could be suffering from abuse issues which have not been dealt with.

\section{Psychodynamic talking treatment}

In deciding which type of patients were suitable for psychoanalytic treatment, Freud (1904) considered that a 'certain measure of natural intelligence and ethical requirement' was necessary (p. 254). There was nothing unique about that exclusion. Freud also doubted the mental elasticity of patients over the age of 50 and those with psychosis. However, he had the humbleness to add, 'I do not regard it as by any means impossible that by suitable changes in the method we may succeed in overcoming this contraindication' (p. 264). Over half a century later, Carl Rogers (1957) stated that people with learning disabilities would not be able to make use of clientcentred therapy. Unfortunately, for nearly 50 years after this, few mental health professionals were interested in testing this hypothesis.

There has been a shared societal fantasy that psychological treatment, especially a talking treatment, requires a high intellect and verbal ability. Although it was postulated (Sinason, 1994; Corbett et al, 1996) that psychodynamic treatment required emotional intelligence rather than cognitive functioning and therefore children and adults with learning disability could benefit from treatment, the 'Woody Allen' effect continued to influence attitudes. (Allen, the American film-maker, made public the huge length

Valerie Sinason is a consultant psychoanalyst and child psychotherapist working in London. She is a consultant research psychoanalyst at St George's Hospital Medical School's Psychiatry of Disability Department and Director of the Clinic for Dissociative Studies. Correspondence: Joan Bicknell Centre, Springfield Hospital, Glenburnie Road, London SW17 7DJ. 
of time of his analysis. This has led some to think of it as a lifetime expensive treatment for the intellectual middle-class, not as something for everyone.)

Only small projects had been undertaken until the consistent work from the 1980s carried out in London at St George's Hospital by Hollins, Bicknell and Sinason (Bicknell, 1983; Hollins \& Grimer, 1988) and the Tavistock Clinic by Sinason, Stokes, Symington and Bichard (Symington, 1981), and in Barnsley by Beaill and Frankish (Beaill, 1989; Frankish, 1989). The Congress of the European Association for Mental Health in Mental Retardation (Amsterdam, 13-16 September 1995) marked the first major international symposium on psychotherapy and learning disability. We can now see the positive impact of the first 20 years of continuous work with this client group.

\section{Lack of psychotherapy provision}

Both nationally and internationally, any form of psychotherapy or counselling is still far too rare a resource (Corbett et al, 1996). Little has changed in the 15 years since Oliver et al (1987) found that only 12 out of 596 children and adults who were seriously self-injuring were receiving psychological treatment. Although more specialist services, including cognitive-behavioural treatment (Turk, 1998), family therapy, creative therapies and psychodynamic therapies, are being developed along the lines recommended by the National Health Service's (NHS) Review for Psychotherapy (Parry, 1993), this is taking a great deal of time. Hopefully, the current Royal College of Psychiatrists' Working Party on Psychotherapy, chaired by Dr Maria McGinnity, will have an impact here. Additionally, the newly formed Institute for Psychotherapy and Disability in Barnsley is about to question those offering therapy training schemes on whether they accept patients with learning disabilities as training cases.

\section{Problems with professional training schemes}

Many professionals wishing to work therapeutically with clients with learning disabilities are held back by overcautious accredited psychotherapy training schemes offered by the British Confederation of Psychotherapists (BCP) and the United Kingdom Council for Psychotherapy (UKCP). These do not accept such patients as training cases, on the grounds that they might prove too emotionally disturbed or do not allow points of therapeutic technique to be revealed. Although some trainees might not not wish to use a patient with learning disability as a training case, the idea that consultant psychiatrists or psychologists in specialist learning disability posts would find such work difficult is clearly incorrect. This fear, which until now has been inadequately contested, has excluded people with a learning disability from equal access, given that training cases require input from senior practitioners and make a subject acceptable to a training organisation. As well as this basic issue, many training organisations are nervous of the interface with the law when taking on any client whose past or current abuse might need other intervention.

It is adult survivors who face the greatest lack of resources: NHS child psychotherapy training schemes have gradually made space for children with a learning disability who have suffered abuse. However, although there has been a small increase in non-intensive work with such children, particularly those with autistic diagnoses, the number of intensive training cases is still relatively small.

\section{Physical and sexual abuse}

It was only 22 years ago that Kempe (1979) first drew the attention of those in the West to the incidence of physical abuse of children. Experienced teachers, psychiatrists, general practitioners and psychotherapists found it hard to believe. Broken bones and bruises could be explained by the acceptable idea that children were clumsy. When awareness of sexual abuse followed shortly afterwards, it met a similarly disbelieving response. The argument presented by those who could not recognise sexual abuse was often that physical abuse, by comparison, could be proved. It was hard for such professionals to accept that it was only 10 years earlier that the 'physical proof' had been dismissed in favour of the assumption of the child's clumsiness.

For many years, it was not possible to debate the damaging emotional consequences of abuse. In the UK, the problem posed by child sexual abuse was not mentioned in Department of Health and Social Security circulars until 1980 (Mrazek et al, 1981).

\section{Definitions of sexual abuse}

There are many definitions of abuse. Schecter \& Roberge (1976) have proposed a core definition: 
'the involvement of dependent, developmentally immature children, and adolescents, in sexual activities that they do not fully comprehend and to which they are unable to give informed consent or that violate social taboos of family roles'.

Linguistically, it is worth considering that, as part of the medicalising of the experience and the devaluing of children, the term 'child abuse' exists rather than 'child rape'. In a similar way, when adults with learning disabilities are raped, they are also spoken of as abuse victims rather than as victims of the criminal offence of rape.

Adult survivors of sexual abuse are referred to as vulnerable adults. The Law Commission (1995) defines a vulnerable person as an adult over 16 who is unable to protect him- or herself against exploitation or significant harm.

It is interesting to note that the term 'survivor' is not usually used for children.

\section{Definitions of physical abuse}

Although an adult hitting an adult is regarded as assault, an adult hitting a child as part of 'reasonable punishment' is not illegal in the UK. Unlike Austria, Croatia, Cyprus, Denmark, Finland, Germany, Latvia, Norway and Sweden, which have banned physical punishment of children, the UK has a cultural problem. The majority of mothers have admitted not only to hitting small children but also to physically assaulting babies less than 1 year old (Anonymous, 2002). This perhaps shows how little emotional support they have received during pregnancy and how they themselves were treated when they were young. The organisation Children are Unbeatable is attempting to change government policy and extend into the family the freedom from physical impingement that currently exists in state schools.

It is worth considering the different impact of terms such as 'physical abuse' compared with 'assault' or 'grievous bodily harm'.

\section{Abuse and learning disability}

In the painful history of abuse and social attitudes, it is important to note (Cooke \& Sinason, 1998) that workers in the field of learning disability drew attention to the problem of abuse and learning disability at the same time that British society first began to tolerate the knowledge that children without disabilities were being abused.
In a critical review of 22 research projects looking into the incidence and prevalence of sexual abuse in learning disability, Westcott (1991) showed that 3 out of the 4 studies with control or comparison groups found children with learning disabilities to be more vulnerable. McCarthy \& Thompson (1992) found that $61 \%$ of the women in their sample and $25 \%$ of the men had been sexually abused. In terms of treatment issues, it is worth noting Varley's (1984) finding that young women with learning disabilities who met a disbelieving response on disclosing abuse were vulnerable to a psychotic breakdown.

Ammerman et al (1988) examined predisposing factors that led to increased risk of abuse and neglect of children with multiple handicaps. They included disruption in mother-infant attachment, greater stress related to care needs and behavioural problems, and increased vulnerability due to communication and/or cognitive limitations. When Ammerman et al (1989) examined 150 consecutive hospital admissions of children and adolescents with multiple handicaps, they found that the most frequent category was physical abuse. They are among the many researchers who have found that abusive behaviour is triggered by the stress evoked by a baby with learning disabilities. Buchanan \& Oliver (1979), who coined the term 'violenceinduced mental handicap' (VIMH), reported that $22 \%$ of patients in residential institutions had been physically abused.

\section{Legal issues}

Professionals treating survivors need to remember that abuse not only has a major clinical impact on the victim, but also that it is a crime. The interface between treatment and legal services is an extremely difficult and crucial one. Where the victim is a child (with or without disabilities) or an adult with learning disabilities, there is an inbuilt inequality of power. Fear of abandonment and threats and injunctions to keep a secret make it difficult enough for the ordinary child to speak. The experience of giving an oath, taking the witness stand and answering questions, especially hostile ones, can be a difficult one for many traumatised children and adults with disabilities. Nevertheless, with some support for their particular difficulties, they can be increasingly successful. The use of preparatory books (e.g. Hollins et al, 1994) can help. The Home Office report Speaking up for Justice (1998) represented a step forward in recognising these additional problems. If enacted, legislation proposed by the Law Commission (1995) regarding vulnerable persons would improve the situation of people with learning disabilities in law (Cooke \& Sinason, 1998). 
Box 1 Respectful treatment of patients with learning disabilities

When meeting patients for the first time, check whether they like to be addressed formally or informally

Give patients the choice of where to sit: this increases their sense of safety and empowerment (some traumatised individuals feel safest when closest to the door so that they know they are free to leave)

Give proper notice of your holiday dates and times when you will not be available

The Youth, Justice and Criminal Evidence Act 1999 attempts to bring special measures into force to aid vulnerable and intimated witnesses at trial (Harney, 2001).

\section{Practical treatment issues}

\section{Trauma theory}

The theory and training that we internalise affects the way in which we approach patients and their presenting problems. Increasingly, workers are finding it important to have an understanding of trauma theory when working with survivors of abuse (Hollins \& Sinason, 2001). Indeed, some (Sinason, 1994) see the disability itself as constituting a trauma, with any abuse representing a compound trauma.

\section{The referral}

Treatment begins from the moment a communication about someone is received. Whether a letter, a phone call or a direct request, it is necessary to consider why someone's emotional predicament has been noticed or acted upon at this particular moment. In what way is the abusive experience documented? Is it hidden in a huge file so that it can hardly be seen or worked through? Is it omitted but hinted at? Is it directly mentioned together with the behavioural communications that have expressed it?

\section{Treating with respect}

In treating survivors with learning disabilities, we need to be aware that an experience of physical abuse (which inevitably includes emotional abuse) or sexual abuse (which intrinsically includes physical and emotional abuse) is an impingement on physical and mental autonomy that involves betrayal and hurt. Abuse is added to whatever stigmatising or traumatic experiences the disability itself has caused, usually resulting in a compound trauma. Although treatment with respect is a crucial clinical issue in work with all patients, for the survivor with learning disabilities it is even more important. Examples of how to ensure respectful treatment are given in Box 1.

\section{Offering choice, agency and transparency}

Abuse is a 'being-done-to' experience. It is important that treatment is understood as a reciprocal relationship in which two people (if it is one-to-one therapy) or several (if it is a family or group) are pooling their thoughts to try to make sense of the emotional predicament of the client. For example, in the psychotherapy service at St George's Hospital Medical School's Psychiatry of Disability Department, all letters about patients are read out to them. Similarly, any letters that therapists are asked to write for courts, social services or psychiatric services are discussed with and composed in conjunction with the patient.

\section{Case vignette}

$\mathrm{Mr}$ A was being physically assaulted by another service-user at his day centre. He had not been able to discuss this with his group home-worker because he felt ashamed. It reminded him of the physical abuse he received as a child, from his father and a schoolteacher. He was referred for therapy when his behaviour deteriorated, oscillating between faecal smearing and lashing out at others. No one had realised that there was a reason for this. His therapist wrote a letter on his behalf: 'I am writing in the presence of $\mathrm{Mr}$ $\mathrm{A}$, at his request and with his permission. He is very sad and frightened at the moment because he is being bullied at his day centre and that is why he has been behaving in a disturbed way.'

\section{Understanding the impact of trauma on behaviour in treatment (Fig. 1)}

\footnotetext{
Case vignette

Mr C walked up and down the corridor all day, looking desperately left and right and then behind him. Psychotherapy, informed by trauma knowledge, revealed that this was hypervigilance. Mr C's father, who had psychotic episodes, used to burst in and attack him. When the therapist was able to explore Mr C's fear that someone else could attack him in the same way, he was slowly able to lessen this defence. Until the reason for his behaviour could be explored, staff felt unable to offer support. They had merely been told that that he was revealing either obsessive or autistic traits or had attention-deficit disorder.
} 
1 The trauma itself

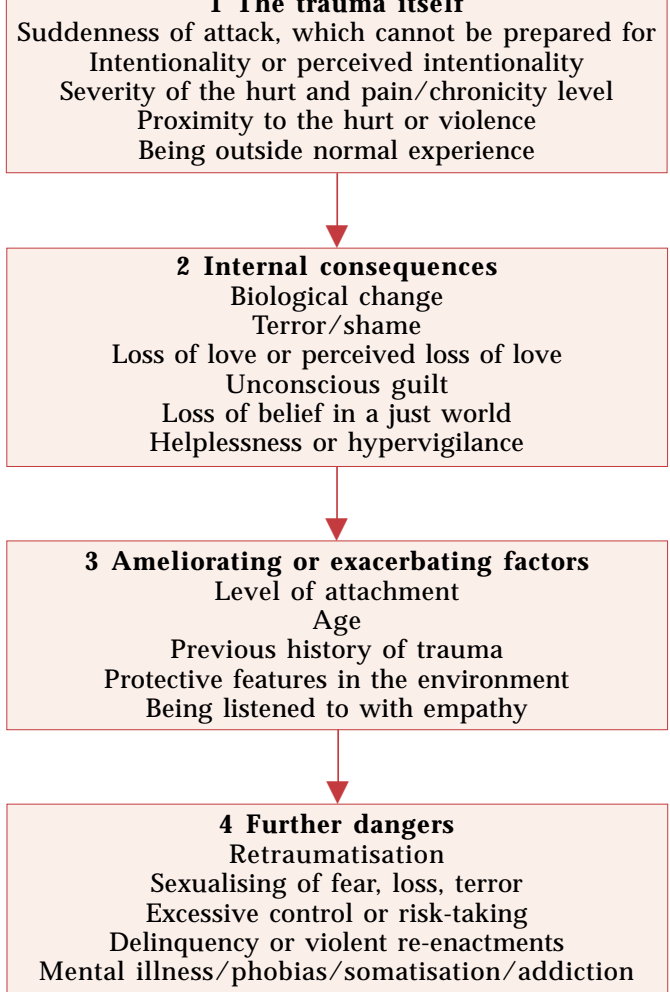

Fig. 1 A summary of trauma and its internal and external consequences

\section{Recognising behavioural communications of trauma}

Misconstruing disturbed and disturbing behaviour is a regular dynamic in abuse and learning disability. For example, excessive masturbating or inappropriate erotic behaviour is all too often dismissed as part of the behaviour of a child or adult with learning disabilities rather than being seen as the possible revelation of disturbing experiences through bodily actions.

The whole range of possible signs and symptoms that apply to all children and adults are relevant to this population, as well as to the more specific one of 'challenging behaviour'. The following lengthy list includes almost every reason for referral to clinics. It is important to note that no sign on its own is a reliable indicator: the full range of symptoms and behaviour should be considered in assessing the probability of sexual abuse.

\section{Childhood problems}

Bedwetting, school phobia, stomach-ache, nightmares, deterioration in schoolwork, inability to concentrate, inappropriate sexualised behaviour, excessive masturbating, self-injury, violence to others, 'challenging' behaviour, faecal smearing.

\section{Problems in adolescence and adulthood}

Bedwetting, promiscuity, running away, drug addiction, prostitution, self-destructive behaviour, eating disorders, abuse of children, violence to others, self-injury, confusion over sexual identity, 'challenging behaviour'.

\section{Gender issues}

Boys and men are more likely to externalise their distress into aggression, but girls and women are more likely to self-injure. It should be noted that boys who are sexually abused are more likely to be suicidal.

\section{Shared effects across ages and genders}

Anxiety, depression, hopelessness and helplessness, low self-esteem, violence to self and others ('challenging behaviour'), post-traumatic stress disorder, dissociation, flashbacks, re-enactments, startle reactions, faecal smearing, urinary incontinence, a drop in IQ owing to a trauma-induced inability to think, hypervigilance.

\section{Passing on abuse}

Although moving from victim to abuser is the rarest result of abuse (Browne, 1993) it is nevertheless profoundly damaging to society, as it extends the cycle of abuse. The following case vignettes are examples of this process.

Example 1: Following rape by another resident, 22year-old Mr B began to smear faeces. Staff found it hard to connect the two events as the symptom was so painful for them to deal with. After treatment had clarified the link, staff became sympathetic and the smearing stopped.

Example 2: 27-year-old Ms C kept wheeling her wheelchair to the furthest part of the room and banging her head against the wall. Staff had tried fitting her with a helmet and padding the wall, but to no avail. In treatment, the link was made with the bad thoughts and memories in her head that she wished she could bang out of existence. The head-banging stopped.

\section{Key psychoanalytic concepts of use in treatment}

\section{Re-enactment}

In order to make sense of experiences which have not been worked through, the individual repeats 
or re-enacts them. This can have a restitutive function. There can be a wish or hope that the traumatic experience can be made digestible. Sometimes it includes a hope for a different outcome. It can be an attempt to bring back the situation that existed prior to the trauma, so that the ego is able to control the memory of it. However, it can also be a primitive defence that does not allow the tension to be worked through. Re-enactments and repetition compulsions thus can link with identifying with the aggressor.

\section{Case vignette}

Steven, aged 14, had a severe learning disability and was extremely violent to other boys in his residential school at playtime. In therapy, it emerged that he had been physically assaulted in his primary school by a group of boys, without disabilities, and nobody had helped him. In his residential school, he would go out at playtime and taunt other boys until they retaliated. Then he would attack them in a frenzied way. In treatment, he was able to see how he hoped to transform the horror of what had happened to him by being the aggressor. Work with the staff led to him being kept safely at playtime until he had understood enough of his processes to go out without needing to undergo a re-enactment.

\section{Splitting}

This describes the way that children, in particular, divide their world into 'goodies' and 'baddies' in the hope of avoiding states of ambivalence. In earliest infancy, this is necessary for the child to avoid being overwhelmed. However, as children grow older, so should their ability to tolerate ambivalence. Adults who view the world in a very split way often have delusional attachments. Here they try to avoid seeing the reality of poor attachments by delusionally 'making good' their understanding of their history.

Example: a middle-aged man with a severe learning disability and with a lifetime of neglect and sexual abuse regularly praised his incestuous mother, who had abandoned him: 'My mother will come and visit me. She is a wonderful mother. She gave me tea and biscuits when I was little. She did not have to feed me. But she loves me.'

\section{Transference}

Sometimes patients transfer their past experiences wholesale to another person such as the therapist.

Example: Mr A, whose father had regularly abused him physically and sexually when drunk, tentatively told me that he could not come for his session the following week as his 'home' was going on a day-trip.
After telling me this, a look of terror appeared on his face and he ran into the corner and huddled against the wall, banging his head. I made a transference interpretation, saying 'You can't come next week and you politely told me. But then you got scared and hid in the corner because you were worried I would be furious with you, just like your father was whenever you did anything he did not want. Perhaps sometimes it feels as though I am your father and not your therapist, who cares about working out with you why you are so frightened'. This was a great relief to him.

\section{Other consequences of abuse that need working on in treatment}

Abuse involves betrayal, shame, secrecy, stigmatisation and self-blame. Children and adults with learning disabilities may already feel a sense of low self-worth as a result of their disability. This means that treatment needs to recognise the impact of double trauma. Survivors with learning disabilities often have the fantasy that their disability is the result of bad parental sex. Hence, the very existence of a disability makes age-appropriate response to abusive encounters more difficult.

On an Oedipal level, the template for loving is usually of a person without learning disabilities. Some victims with disabilities who are emotionally disturbed can assist the perpetrator by seeing him (or her) as a helper. Indeed, the perpetrator may be seen as a parental figure, thus meeting an Oedipal fantasy. This leads to further guilt.

At a deeper level, every child and adult with learning disability that I have treated has, at some point during therapy, expressed the fear that the therapist would wish that they had been aborted. This fear of being killed, enhanced by primitive annihilation terrors, leads to further appeasement of adults without disabilities.

Faced with dependency needs that go beyond the normal chronological level, it can be easier to regress to a pre-birth state and refuse a psychological birth (Mahler et al, 1975) into a world of difference. The child and adult with learning disabilities may be dependent on others for help with basic toileting and dressing functions. This makes it far harder for them to say 'no' to being touched because without the helper, they would not survive.

Sexualisation is a way of defending the self against pain and fear. Sexualised behaviour brings with it stigmatisation. Promiscuity, paedophiliac fantasies and chronic masturbation can be byproducts of the original abuse. Finally, and most worryingly, the more vulnerable victims might pass on the indigestible experience and this could lead to the extension of cycles of abuse. 


\section{Case vignette}

Steven was in enormous distress. A 22-year-old man with a severe disability, he had been moved into a group home opposite a boys' secondary school. Even though he had told his social worker that seeing little boys 'makes me feel funny', this had been ignored. He had been referred for treatment following indecent exposure. He was filled with fantasies about befriending the children he saw. It turned out that he had been abused by a teacher during his first year of secondary boarding school at the age of 11 His disturbed behaviour following the abuse had been misdiagnosed as resulting from disability and had therefore been ignored. Becoming a man and having the potential to behave like his aggressor for the first time, he was taken by surprise by the sudden rush of intense fantasy longings. The refusal of social services to take his fears seriously led to self-injury and finally an indecent assault on a child. Once in therapy, it took time for him to be able to get back to the feeling of terror and betrayal that his own abuse evoked. He spoke movingly of his wish to kill himself, especially as he was 'thick too'. The abuse had resurrected his low self-esteem from his learning disability. The sight of the young, hopeful boys starting their new school had brought him an unbearable reminder of his own hopes for school and of his innocence. He could not stand the sight of those innocent boys and wanted to kill himself in them. It was only as those feelings were explored that he could have empathy for his own child-self and move from that to empathy for other victims. Only then could he move from being a victim and a victim/perpetrator to a survivor.

Consultant psychiatrists who note the possible traumatic aetiology of disturbed behaviour provide the possibility of ending a cycle of abuse.

\section{References}

Ammerman, R. T., Lubetsky, M. J., Hersen, M. et al (1988) Maltreatment of children and adolescents with multiple handicaps: five case examples. Journal of the Multihandicapped Person, 1, 129-139.

- Van Hasselt, V. B., Hersen, M., et al (1989) Abuse and neglect in psychiatrically hospitalised multihandicapped children. Child Abuse and Neglect, 13, 335-343.

Anonymous (2002) Children are Unbeatable Newsletter, 9 January. Beaill, N. (1989) Understanding emotion. In Mutual Respect: Therapeutic Approaches to People Who Have Learning Difficulties (ed. D. Brandon), pp. 27-45. Surbiton: Good Impressions

Bicknell, J. (1983) The psychotherapy of handicap. British Journal of Medical Psychology, 56, 167-168.

Browne, K. (1993) Violence in the family and its links with child abuse. In Clinical Paediatrics, Child Abuse (eds C. J. Hobbs \& J. M. Wynne), pp. 149-165. London: Baillière Tindall.

Buchanan, A. \& Oliver, J. E. (1979) Abuse and neglect as a cause of mental retardation. Child Abuse and Neglect, 3 , $467-475$.

Cooke, L. B. \& Sinason, V. (1998) Abuse of people with learning disabilities and other vulnerable adults. Advances in Psychiatric Treatment, 4, 119-125.

Corbett, A., Cottis, T. \& Morris, S. (1996) Witnessing, Nurturing, Protesting: Therapeutic Responses to Sexual Abuse of People with Learning Disabilities. London: David Fulton.
Frankish, P. (1989) Meeting the emotional needs of handicapped people: a psychodynamic approach. Journal of Mental Deficiency Research, 33, 407-414.

Freud, S. (1904) Freud's psychoanalytic procedure. Reprinted (1953-1974) in the Standard Edition of the Complete Psychological Works of Sigmund Freud (trans. and ed. by J. Strachey), vol. 7. London: Hogarth Press.

Harney, N. (2001) Vulnerable adult abuse. Association of Child Abuse Lawyers, Issue 4.

Hollins, S. \& Grimer, (1988) Going Somewhere. Pastoral Care for People with Mental Handicap. London: SPCK.

— \& Sinason, V. (2001) Psychotherapy, learning disabilities and trauma, new perspectives. British Journal of Psychiatry, 176, 32-36.

_- _ \& Boniface, J. (1994) Going to Court. London: St George's Mental Health Library in association with VOICE UK.

Home Office (1998) Speaking up for Justice. London: HMSO

Kempe, C. H. (1979) Incest and Other Forms of Sexual Abuse. London: Fontana.

Law Commission (1995) Mental incapacity. In Fourth Programme of Law Reform: Mentally Incapacitated Adults, Report No. 231, Part IX. London: HMSO.

Mahler, M., Pine, F. \& Bergman, A. (1975) The Psychological Birth of the Human Infant. New York: Basic Books.

McCarthy, M. \& Thompson, D. (1992) Sex and the Three Rs, Rights, Responsibilities and Risks: A Sex Education Package for Working with People with Learning Difficulties. Brighton: Pavilion.

Mrazek, P. B., Lynch, M. \& Bentovim, A. (1981) Recognition of child sexual abuse in the United Kingdom. In Sexually Abused Children and Their Families (eds P. B. Mrazek \& C. H. Kemp). Oxford: Pergamon.

Oliver, C., Murphy, G. \& Corbett, J. (1987) Self-injurious behaviour in people with mental handicaps: a total population study. Journal of Mental Deficiency Research, 31, 147-162.

Parry, G. (1993) National Health Service Review for Psychotherapy. London: HMSO.

Rogers, C. (1957) The necessary and sufficient conditions of therapeutic personality change. Journal of Consulting Psychology, 21, 95-103.

Schecter, M. D. \& Roberge, L. (1976) Sexual exploitation. In Child Abuse and Neglect: the Family in the Community (eds R. E. Helfer \& C. H. Kempe). Cambridge, MA: Ballinger.

Sinason, V. (1994) Mental Handicap and the Human Condition. London: Free Association Books.

Symington, N. (1981) The psychotherapy of a subnormal patient. British Journal of Medical Psychology, 54, 187-199.

Turk, J. (1998) Children with learning disabilities and their parents. In Cognitive Behaviour Therapy for Children and Families (ed. G. Philip). Cambridge: Cambridge University Press.

Varley, C. K. (1984) Schizophreniform psychoses in mentally retarded adolescent girsl following sexual assault. American Journal of Psychiatry, 141, 593-595.

Westcott, H. (1991) The abuse of disabled children: a review of the literature. Child: Care, Health and Development, 17, $243-258$.

\section{Multiple choice questions}

1. Treatment for people with learning disabilities who have been sexually or physically abused:

a is easy to access

b was advocated by Freud

c is a major part of psychotherapy training schemes

d has received less attention than abuse of people without disabilities

e has been officially recognised for nearly 20 years. 
2. Behavioural communications following abuse can include:
a aggressive, challenging behaviour
b inappropriate sexual behaviour
c incontinence
d faecal smearing
e suicidal behaviour.

3. Basic themes in therapy with survivors include:
a happiness at being different
b fear of being annihilated
c shame at being different
d enjoyment of independence
e sexual disturbance.

4. Optimising treatment for survivors includes:

a allowing as much personal agency as possible

b using the same techniques as used with patients without disabilities

c clearly informing them of your holiday dates and times when you will not be available

d notifying them of any letters you write or reports you receive about them

e playing down traumatic aetiology.
5. Abuse of patients with learning disabilities:

a involves betrayal

b does not hurt as much as abuse of more-aware survivors

c was easy for professionals to accept

d often involves traumatisation

e can often exacerbate the emotional problems of learning disability.

\section{Commentary}

\section{Earl Hopper}

It is very difficult to teach and learn about the survival of trauma by those with learning disabilities, especially the young, because when we take on board the scope of the problem and the magnitude of the despair and desperation associated with it, we all experience extreme anxiety.

Valerie Sinason's article (2002, this issue) contains a vast amount of information. It would be very useful as the basis of a series of seminars in which the topics raised could be discussed and in which participants were able to examine their own feelings and fantasies associated with them. We are reminded of the strength and prevalence of denial concerning the suffering of children who are abused, which, in the case of those with learning disabilities, is even more extreme. Such denial exists not only

Earl Hopper is a psychoanalyst, group analyst and organisational consultant in private practice in London, where he is an honorary tutor at The Tavistock \& Portman NHS Trust. He is also on the Faculty of the Post-Doctoral Program in Group Psychotherapy of Adelphi University in the USA. He is a past-President of the International Association of Group Psychotherapy and a past-Chairman of the Group of Independent Psychoanalysts of the British Psychoanalytical Society. Correspondence: 11 Heath Mansions, The Mount, London NW3 6SN, UK. 